Article

\title{
New Andrastin-Type Meroterpenoids from the Marine-Derived Fungus Penicillium sp.
}

\author{
Jinwei Ren ${ }^{1,2,+}$, Ruiyun Huo ${ }^{1,2,+}$, Gaoran Liu ${ }^{1,2}$ and Ling Liu ${ }^{1,2, *(D)}$ \\ 1 State Key Laboratory of Mycology, Institute of Microbiology, Chinese Academy of Sciences, Beijing 100101, \\ China; renjw@im.ac.cn (J.R.); ruiyunhuo@163.com (R.H.); liugaoran@163.com (G.L.) \\ 2 College of Life Sciences, University of Chinese Academy of Sciences, Beijing 100039, China \\ * Correspondence: liul@im.ac.cn; Tel.: +86-10-64806153 \\ + These authors contributed equally to this work.
}

check for

updates

Citation: Ren, J.; Huo, R.; Liu, G.; Liu, L. New Andrastin-Type Meroterpenoids from the Marine-Derived Fungus Penicillium sp. Mar. Drugs 2021, 19, 189. https:// doi.org/10.3390/md19040189

Academic Editor: Bin Wu

Received: 27 February 2021

Accepted: 23 March 2021

Published: 27 March 2021

Publisher's Note: MDPI stays neutral with regard to jurisdictional claims in published maps and institutional affiliations.

Copyright: (c) 2021 by the authors. Licensee MDPI, Basel, Switzerland. This article is an open access article distributed under the terms and conditions of the Creative Commons Attribution (CC BY) license (https:// creativecommons.org/licenses/by/ $4.0 /)$.

\begin{abstract}
Three new andrastin-type meroterpenoids penimeroterpenoids A-C (1-3) together with two known analogs (4 and 5) were isolated from the cultures of the marine-derived Penicillium species (sp.). The structures of the new compounds were elucidated on the basis of 1- and 2-dimensional (1D/2D) Nuclear Magnetic Resonance (NMR) spectroscopic and mass spectrometric analysis. The absolute configurations of 1-3 were determined by comparison of experimental and calculated electronic circular dichroism (ECD) spectra. Compound 1 showed moderate cytotoxicity against A549, HCT116, and SW480 cell lines.
\end{abstract}

Keywords: marine-derived fungus; secondary metabolites; meroterpenoids; absolute configurations; cytotoxicity

\section{Introduction}

Meroterpenoids are hybrid natural products with partial structure fragments derived from terpenoids [1,2]. Based on biosynthetic origins, meroterpenoids can be sorted into polyketide-terpenoids and nonpolyketide-terpenoids [1,2]. The andrastin-type meroterpenoids derived from 5-dimethylorsellinic acid (DMOA) and farnesyl diphosphate (FPP) via a mixed polyketide-terpenoid pathway are characterized by a five-methyl substituted ent- $5 \alpha, 14 \beta$-androstane skeleton (6,6,6,5-tetracarbocyclic skeleton) [3,4]. Since citreohybridones A and B were isolated in 1991, over 30 analogues have been isolated and characterized [5-14]. Many andrastin-type meroterpenoids have shown potent cyotoxic, antifeedant, and insecticidal activities $[4,8,10]$. Andrastin-type meroterpenoids have attracted much attention from synthetic chemists due to their structural and biological diversity [15-17]. In recent years, the biosynthetic pathways involved in andrastin-type meroterpenoid production have been well-elucidated [4,14,18,19].

Marine-derived fungi, living under extreme environmental conditions such as high salinity, intensely high pressure, absence of sunlight, and deficiency of nutrients, are considered to be a new reservoir of structurally diverse and biologically active metabolites for drug discovery [20,21]. In our ongoing search for new bioactive secondary metabolites from marine-derived fungi, the fungus Penicillium sp. (A18), isolated from a deep-water sediment sample that was collected at a depth of $5115 \mathrm{~m}$ in the East Pacific, was selelected for chemical investigations. As a result, three new andrastin-type meroterpenoids, which have been named penimeroterpenoids A-C (1-3), together with two known compounds, andrastone E (4) [22] and citreohybridonol (5) [11] (Figure 1), were isolated and identified from the culture extract of the fungus. Their structures were established by a detailed interpretation of 1D/2D NMR spectroscopic and mass spectrometric data, and the absolute configurations of 1-3 were determined by electronic circular dichroism (ECD) calculations. All of these compounds were evaluated for cytotoxicity against a panel of six human tumor 
cell lines. Herein, the details of the isolation, structure elucidation, and biological activity of these compounds (Figure 1) are described.

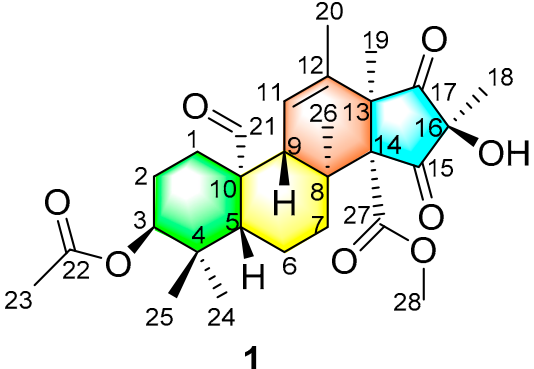

(1)

4

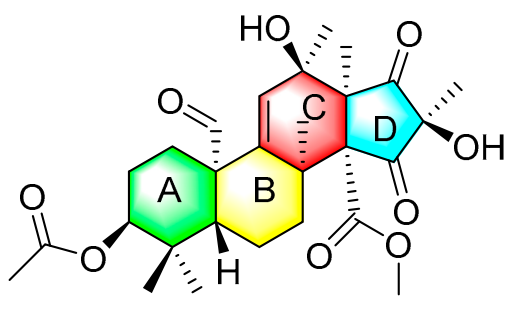

2

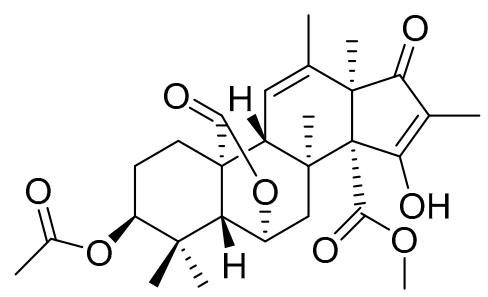

5

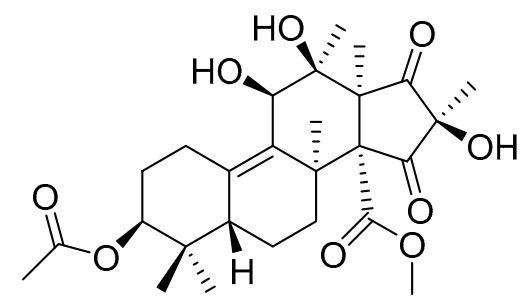

3

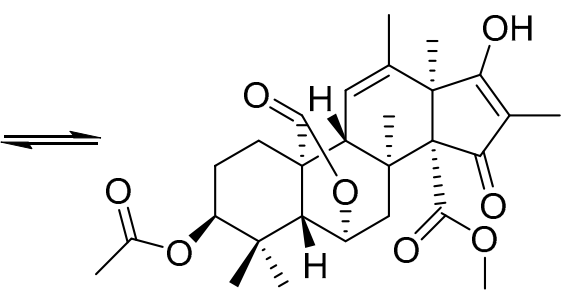

Figure 1. Structures of compounds 1-5.

\section{Results}

Penimeroterpenoid A (1) was obtained as a colorless oil. Its molecular formula $\mathrm{C}_{28} \mathrm{H}_{38} \mathrm{O}_{8}$ was established by high-resolution electrospray ionisation mass spectrometry (HRESIMS) analysis $\left(\mathrm{m} / \mathrm{z} 525.2454[\mathrm{M}+\mathrm{Na}]^{+}\right)$, indicating ten degrees of unsaturation. The infrared (IR) spectrum showed the presence of hydroxy $\left(3445 \mathrm{~cm}^{-1}\right)$ and carbonyl $\left(1752 \mathrm{~cm}^{-1}\right)$ groups. Analysis of its NMR data (Table 1) revealed the presence of eight methyl groups, four methylenes, three methines (including one oxymethine), six sp ${ }^{3}$ quarternary carbons (one oxygenated), one trisubstituted olefin unit, two carboxylic carbons $\left(\delta_{\mathrm{C}} 167.3,170.7\right)$, one aldehyde group $\left(\delta_{\mathrm{C}} 204.5 ; \delta_{\mathrm{H}} 10.1\right)$, and two ketone carbons $\left(\delta_{\mathrm{C}} 210.6\right.$, 206.8, respectively). These data accounted for all ${ }^{1} \mathrm{H}$ and ${ }^{13} \mathrm{C}$ NMR resonances except for one exchangeable proton, suggesting that 1 was a tetracyclic compound. Analysis of the ${ }^{1} \mathrm{H}_{-}{ }^{1} \mathrm{H}$ correlation spectroscopy (COSY) NMR data (Figure 2) led to the identification of three isolated spin-systems of C-1-C-2-C-3, C-5-C-6-C-7, and C-9-C-11. Heteronuclear multiple bond correlations (HMBC) from $\mathrm{H}_{2}-1$ to C-10, $\mathrm{H}-3$ to $\mathrm{C}-5, \mathrm{H}-5$ to $\mathrm{C}-1, \mathrm{C}-4, \mathrm{C}-10$, $\mathrm{C}-24$, and $\mathrm{C}-25$, and from the geminal methyl groups $\mathrm{H}_{3}-24$ and $\mathrm{H}_{3}-25$ to $\mathrm{C}-3, \mathrm{C}-4$, and $\mathrm{C}-5$ completed the cyclohexane ring (ring A). HMBC cross-peaks from $\mathrm{H}-3$ and $\mathrm{H}_{3}-23$ to the carboxylic carbon C-22 $\left(\delta_{\mathrm{C}} 170.7\right)$ established the location of the acetyl group at C-3. Other correlations from $\mathrm{H}-5$ to the aldehyde carbon $\mathrm{C}-21$, and from the aldehyde proton $\mathrm{H}-21$ to $\mathrm{C}-1$ and $\mathrm{C}-10$ indicated that $\mathrm{C}-21$ was attached to $\mathrm{C}-10$. While the HMBC cross-peaks from $\mathrm{H}_{2}-1$ and $\mathrm{H}-5$ to $\mathrm{C}-9, \mathrm{H}_{2}-7$ to $\mathrm{C}-8$ and C-26, H-9 to C-8, C-10, C-21, and C-26, and from $\mathrm{H}_{3}-26$ to $\mathrm{C}-7, \mathrm{C}-8, \mathrm{C}-9$, and $\mathrm{C}-14$ permitted the completion of another cyclohexane unit (ring B) with the methyl carbon C-26 and the $\mathrm{sp}^{3}$ quarternary carbon $\mathrm{C}-14\left(\delta_{\mathrm{C}} 70.6\right)$ attached at C-8. HMBC correlations from H-9 to C-12, H-11 to C-8, C-10, C-13, C-20, $\mathrm{H}_{3}-19$ to $\mathrm{C}-12, \mathrm{C}-13, \mathrm{C}-14$, and $\mathrm{C}-17$, and from $\mathrm{H}_{3}-20$ to $\mathrm{C}-11, \mathrm{C}-12$, and $\mathrm{C}-13$, as well as from $\mathrm{H}_{3}-18$ to $\mathrm{C}-16$ and two ketone carbons (C-15 and C-17: $\delta_{\mathrm{C}} 210.6$ and 206.8 , respectively) permitted the completion of the tetrahydro- $1 H$-indene-1,3(2H)-dione moiety (rings $\mathrm{C}$ and D), fused with the cyclohexane ring $B$ at C-8 and C-9. In addition, HMBC correlations from $\mathrm{H}_{3}-28$ to the carboxylic carbon $\mathrm{C}-27\left(\delta_{\mathrm{C}} 167.3\right)$ located the methoxy group at C-27. The exchangeable proton was located at C-16 by default, an identification supported by the chemical shift value for $\mathrm{C}-16\left(\delta_{\mathrm{C}} 72.1\right)$. Thus, the planar structure of $\mathbf{1}$ was established as shown (Figure 1), and has the same planar structure as compound 4. 
Table 1. ${ }^{1} \mathrm{H}$ NMR and ${ }^{13} \mathrm{C}$ NMR data (500 and $125 \mathrm{MHz}$ ) for $1-3$ in $\mathrm{CDCl}_{3}$.

\begin{tabular}{|c|c|c|c|c|c|c|}
\hline \multirow{2}{*}{ Position } & \multicolumn{2}{|c|}{1} & \multicolumn{2}{|l|}{2} & \multicolumn{2}{|c|}{3} \\
\hline & $\delta_{\mathrm{H}}(J$ in $\mathrm{Hz})$ & $\delta_{\mathrm{C}}$ & $\delta_{\mathrm{H}}(J$ in $\mathrm{Hz})$ & $\delta_{\mathrm{C}}$ & $\delta_{\mathrm{H}}(J$ in $\mathrm{Hz})$ & $\delta_{\mathrm{C}}$ \\
\hline $1 \mathrm{a}$ & $2.32, \mathrm{~m}$ & $27.8, \mathrm{CH}_{2}$ & 2.31, dt (12.9 5.5) & $26.6 \mathrm{CH}_{2}$ & $2.75, \mathrm{~m}$ & $23.1, \mathrm{CH}_{2}$ \\
\hline $1 b$ & $1.01, \mathrm{dt}(12.05 .5)$ & & $1.01, \mathrm{~m}$ & & $2.03, \mathrm{~m}$ & \\
\hline 2 & $1.59, \mathrm{~m}$ & $23.4, \mathrm{CH}_{2}$ & $1.71, \mathrm{~m}$ & 23.6, $\mathrm{CH}_{2}$ & $1.82, \mathrm{~m}$ & $26.3, \mathrm{CH}_{2}$ \\
\hline 3 & $4.65, \mathrm{~m}$ & $77.1, \mathrm{CH}$ & $4.65, \mathrm{t}(2.5)$ & $76.9, \mathrm{CH}$ & $4.73, \mathrm{t}(2.5)$ & $77.7, \mathrm{CH}$ \\
\hline 4 & & $37.0, \mathrm{C}$ & & $37.4, \mathrm{C}$ & & $38.7, \mathrm{C}$ \\
\hline 5 & $1.78, \mathrm{~m}$ & $47.7, \mathrm{CH}$ & $1.80, \mathrm{~m}$ & $46.0, \mathrm{CH}$ & $2.45, \mathrm{dd}(11.1,6.8)$ & $41.8, \mathrm{CH}$ \\
\hline $6 a$ & $2.02, \mathrm{~m}$ & $16.9, \mathrm{CH}_{2}$ & $2.16, \mathrm{~m}$ & $16.9, \mathrm{CH}_{2}$ & $1.62, \mathrm{~m}$ & $18.2, \mathrm{CH}_{2}$ \\
\hline $6 \mathrm{~b}$ & $1.81, \mathrm{~m}$ & & $1.81, \mathrm{~m}$ & & $1.62, \mathrm{~m}$ & \\
\hline $7 a$ & $2.81, \operatorname{td}(13.5,3.5)$ & $30.8, \mathrm{CH}_{2}$ & $2.84, \operatorname{td}(13.1,4.4)$ & $32.6, \mathrm{CH}_{2}$ & $2.72, \mathrm{~m}$ & 29.7, $\mathrm{CH}_{2}$ \\
\hline $7 \mathrm{~b}$ & $2.36, \mathrm{~m}$ & & $2.09, \mathrm{~m}$ & & $1.95, \mathrm{~m}$ & \\
\hline 8 & & $38.6, \mathrm{C}$ & & $39.7, \mathrm{C}$ & & $39.3, \mathrm{C}$ \\
\hline 9 & $2.19, \mathrm{~s}$ & $53.5, \mathrm{CH}$ & $2.19, \mathrm{~s}$ & $147.9, \mathrm{C}$ & & 132.7, C \\
\hline 10 & & $52.3, \mathrm{C}$ & & 55.1, C & & $141.9, \mathrm{C}$ \\
\hline 11 & $5.82, \mathrm{~s}$ & $126.4, \mathrm{CH}$ & $5.55, \mathrm{~s}$ & $125.8, \mathrm{CH}$ & $4.75, \mathrm{~s}$ & $70.8, \mathrm{CH}$ \\
\hline 12 & & $132.9, \mathrm{C}$ & & 76.0, C & & $79.4, \mathrm{C}$ \\
\hline 13 & & $60.9, \mathrm{C}$ & & $53.1, \mathrm{C}$ & & $55.0, \mathrm{C}$ \\
\hline 14 & & $70.6, \mathrm{C}$ & & $71.8, \mathrm{C}$ & & $72.7, \mathrm{C}$ \\
\hline 15 & & $210.6, C$ & & 202.0, C & & 197.7, C \\
\hline 16 & & 72.1, C & & $75.6, \mathrm{C}$ & & $77.0, \mathrm{C}$ \\
\hline 17 & & $206.8, C$ & & $202.3, \mathrm{C}$ & & $204.4, C$ \\
\hline 18 & $1.38, \mathrm{~s}$ & $19.6, \mathrm{CH}_{3}$ & $1.31, \mathrm{~s}$ & $7.6, \mathrm{CH}_{3}$ & $1.26, \mathrm{~s}$ & $7.4, \mathrm{CH}_{3}$ \\
\hline 19 & $1.29, \mathrm{~s}$ & $16.4, \mathrm{CH}_{3}$ & $1.25, \mathrm{~s}$ & $10.4, \mathrm{CH}_{3}$ & $1.42, \mathrm{~s}$ & $10.8, \mathrm{CH}_{3}$ \\
\hline 20 & $1.68, \mathrm{~s}$ & $18.9, \mathrm{CH}_{3}$ & $1.26, \mathrm{~s}$ & $24.4, \mathrm{CH}_{3}$ & $1.36, \mathrm{~s}$ & $22.2, \mathrm{CH}_{3}$ \\
\hline 21 & $10.1, \mathrm{~s}$ & 204.5, CH & 10.1, s & 202.1, CH & & $170.8, \mathrm{CH}$ \\
\hline 22 & & $170.7, \mathrm{C}$ & & $170.9, \mathrm{C}$ & $2.12, \mathrm{~s}$ & 21.3, $\mathrm{CH}_{3}$ \\
\hline 23 & $2.10, \mathrm{~s}$ & 21.3, $\mathrm{CH}_{3}$ & $2.10, \mathrm{~s}$ & $21.6, \mathrm{CH}_{3}$ & $0.87, \mathrm{~s}$ & 21.3, $\mathrm{CH}_{3}$ \\
\hline 24 & $0.88, \mathrm{~s}$ & $21.4, \mathrm{CH}_{3}$ & $0.93, \mathrm{~s}$ & $21.4, \mathrm{CH}_{3}$ & $1.00, \mathrm{~s}$ & $24.8, \mathrm{CH}_{3}$ \\
\hline 25 & $0.94, \mathrm{~s}$ & $26.5, \mathrm{CH}_{3}$ & $0.96, \mathrm{~s}$ & $26.8, \mathrm{CH}_{3}$ & $1.75, \mathrm{~s}$ & $24.8, C$ \\
\hline 26 & $1.15, \mathrm{~s}$ & $19.9, \mathrm{CH}_{3}$ & $1.44, \mathrm{~s}$ & $26.2, \mathrm{CH}_{3}$ & & 168.0, C \\
\hline 27 & & 167.3, C & & $167.5, \mathrm{C}$ & $3.61, \mathrm{~s}$ & $52.0, \mathrm{CH}_{3}$ \\
\hline 28 & $3.61, \mathrm{~s}$ & $52.0, \mathrm{CH}_{3}$ & $3.62, \mathrm{~s}$ & $52.3, \mathrm{CH}_{3}$ & & \\
\hline
\end{tabular}
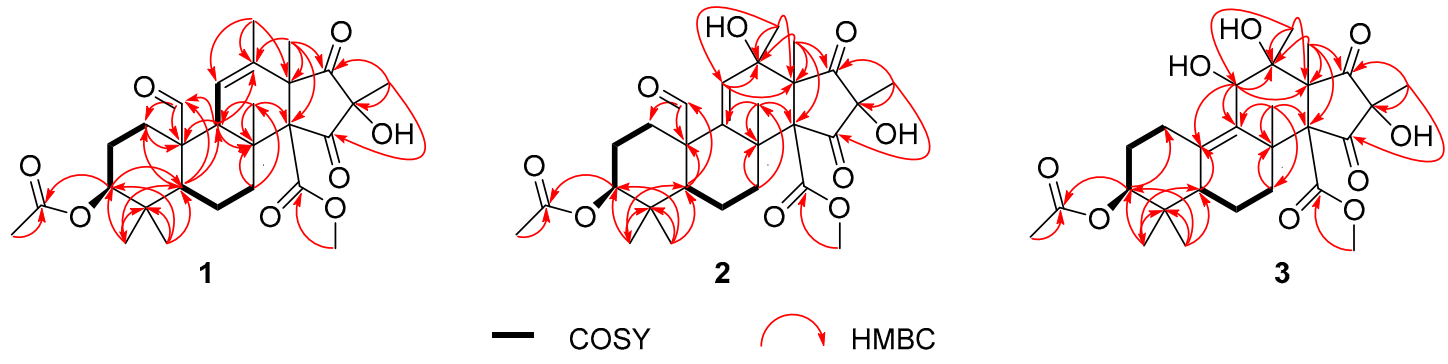

Figure 2. Key correlation spectroscopy (COSY) correlations and heteronuclear multiple bond correlations (HMBC) of 1-3.

The relative configuration of $\mathbf{1}$ was assessed by analysis of the nuclear overhauser effect spectroscopy (NOESY) correlations (Figure 3). NOESY correlations of H-5 with H-7a, $\mathrm{H}-9$, and $\mathrm{H}_{3}-25$ indicated that these protons are all on the same side of the ring system. While NOESY correlations of $\mathrm{H}-3$ with $\mathrm{H}_{3}-24, \mathrm{H}_{3}-26$ with $\mathrm{H}-7 \mathrm{~b}$ and $\mathrm{H}-21$, and of $\mathrm{H}_{3}-28$ with $\mathrm{H}_{3}-19$ and $\mathrm{H}_{3}-18$ placed these protons on the opposite side of the tetracyclic system. Futhermore, the NOESY correlation between $\mathrm{H}-9$ and $\mathrm{H}_{3}-18$ in $\mathbf{1}$ disappeared compared to 4 , and the carborn signal for C-16 and C-18 was shifted upfield by 3.8 and 5.8 ppm, suggesting an inversion of the $\mathrm{C}-16$ stereocenter. These observations led to the assignment of the relative configuration of $\mathbf{1}$, indicating that 1 was the $C-16$ epimer of compound 4 . 

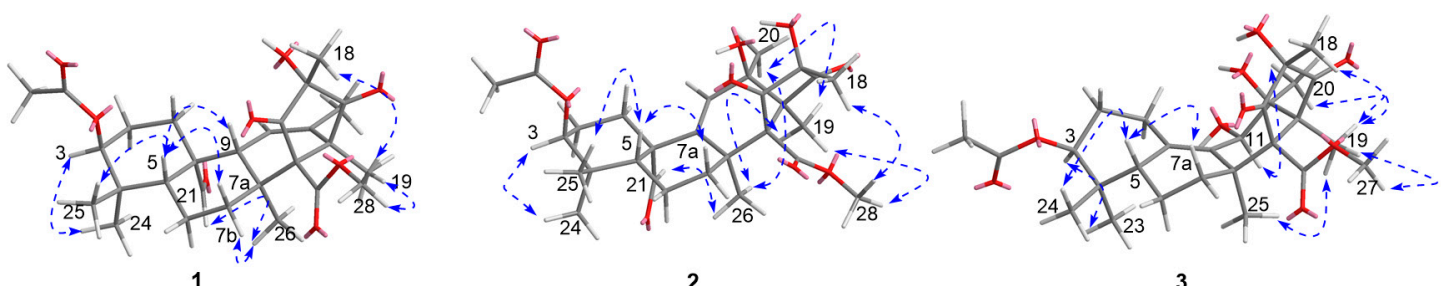

2

NOE

Figure 3. Key nuclear overhauser effect spectroscopy (NOESY) correlations of 1-3.

The absolute configuration of 1 was assessed by comparison of the experimental and simulated ECD spectra generated by the time-dependent density functional theory (TDDFT) for two enantiomers $(3 S, 5 R, 8 S, 9 R, 10 S, 13 R, 14 R, 16 R)-\mathbf{1}(\mathbf{1 a})$ and $(3 R, 5 S, 8 R, 9 S, 10 R, 13 S, 14 S$, 16S)-1 (1b). The MMFF94 conformational search and density functional theory (DFT) reoptimization at the CAM-B3LYP/6-31G(2d,p) level yielded nine lowest-energy conformers for $\mathbf{1 a}$ (Figure S22). The overall calculated ECD spectra of $\mathbf{1 a}$ and $\mathbf{1} \mathbf{b}$ were then generated by Gaussian broadening (Figure 4). The experimental ECD spectrum of 1 was nearly identical to the calculated ECD spectrum for 1a, clearly indicating the $3 S, 5 R, 8 S, 9 R, 10 S, 13 R, 14 R, 16 R$ absolute configuration for $\mathbf{1}$.

Penimeroterpenoid B (2) was also obtained as a colorless oil. The molecular formula was determined as $\mathrm{C}_{28} \mathrm{H}_{38} \mathrm{O}_{9}$ (ten degrees of unsaturation) by HRESIMS ( $\mathrm{m} / z$ 541.2402 [M $+\mathrm{Na}^{+}$), which is 16 mass units higher than that of $\mathbf{1}$. The IR spectroscopy indicated the presence of hydroxy $\left(3421 \mathrm{~cm}^{-1}\right)$ and carbonyl $\left(1757 \mathrm{~cm}^{-1}\right)$ groups. Analysis of its NMR data (Table 1) revealed the presence of the same partial structure as that found in 1, except that those corresponding to the cyclohexene ring (ring B) in $\mathbf{1}$ were different in $\mathbf{2}$. Notably, the resonances for a methine unit $\left(\delta_{\mathrm{H}} / \delta_{\mathrm{C}} 2.19 / 53.5, \mathrm{C}-9\right)$, one C-11/C-12 olefin $\left(\delta_{\mathrm{H}} / \delta_{\mathrm{C}}\right.$ $5.82 / 126.4 ; 132.9)$, and one methyl $\left(\delta_{\mathrm{H}} / \delta_{\mathrm{C}} 1.68 / 18.9, \mathrm{C}-20\right)$ in 1 were replaced by those for one C-9/C-11 olefin $\left(\delta_{\mathrm{H}} / \delta_{\mathrm{C}} 5.55 / 125.8 ; 147.9\right)$, one oxygenated sp $\mathrm{s}^{3}$ quarternary carbon $\left(\delta_{\mathrm{C}}\right.$ $76.0, \mathrm{C}-12)$, and one methyl group $\left(\delta_{\mathrm{H}} / \delta_{\mathrm{C}} 1.26 / 24.3, \mathrm{C}-20\right)$ in the spectra of 2 , indicating that the double bond at C-11/C-12 was transferred to C-9/C-11. These observations were also confirmed by HMBC correlations (Figure 2) from H-11 to C-8, C-9, C-10, C-12, C-13, and $\mathrm{C}-20$, and from $\mathrm{H}_{3}-20$ to $\mathrm{C}-11, \mathrm{C}-12$, and $\mathrm{C}-13$. On the basis of these data, the gross structure of 2 was established as shown. Compound 2 was deduced to have the same relative configuration as $\mathbf{1}$ by a comparison of their NOESY data (Figure 3). In the NOESY spectrum, the cross-peaks of $\mathrm{H}-5$ with $\mathrm{H}-7 \mathrm{a}$ and $\mathrm{H}_{3}-25$ demonstrated that these protons were cofacial and were arbitrarily assigned as $\beta$-orientations. Meanwhile, the NOESY correlations of $\mathrm{H}-3$ with $\mathrm{H}_{3}-24, \mathrm{H}_{3}-26$ with $\mathrm{H}_{3}-19, \mathrm{H}_{3}-20, \mathrm{H}-21$, and $\mathrm{H}_{3}-28$, and of $\mathrm{H}_{3}-28$ with $\mathrm{H}_{3}-18$ and $\mathrm{H}_{3}-19$ indicated that these groups were correspondingly assigned as $\alpha$-orientations. The absolute configuration for 2 was also proposed by a comparison of the experimental and calculated ECD spectra for the enantiomers $(3 S, 5 R, 8 S, 10 S, 12 R, 13 S, 14 R, 16 R)-2$ (2a) and $(3 R, 5 S, 8 R, 10 R, 12 S, 13 R, 14 S, 16 S)-\mathbf{2}(\mathbf{2} \mathbf{b})$. The calculated ECD spectrum of $\mathbf{2 a}$ showed a good agreement with the experimental one (Figure 4 ), which supported the absolute configuration being $3 S, 5 R, 8 S, 10 S, 12 R, 13 S, 14 R, 16 R$. Thus, the structure of 2 was elucidated, as depicted in Figure 1. 

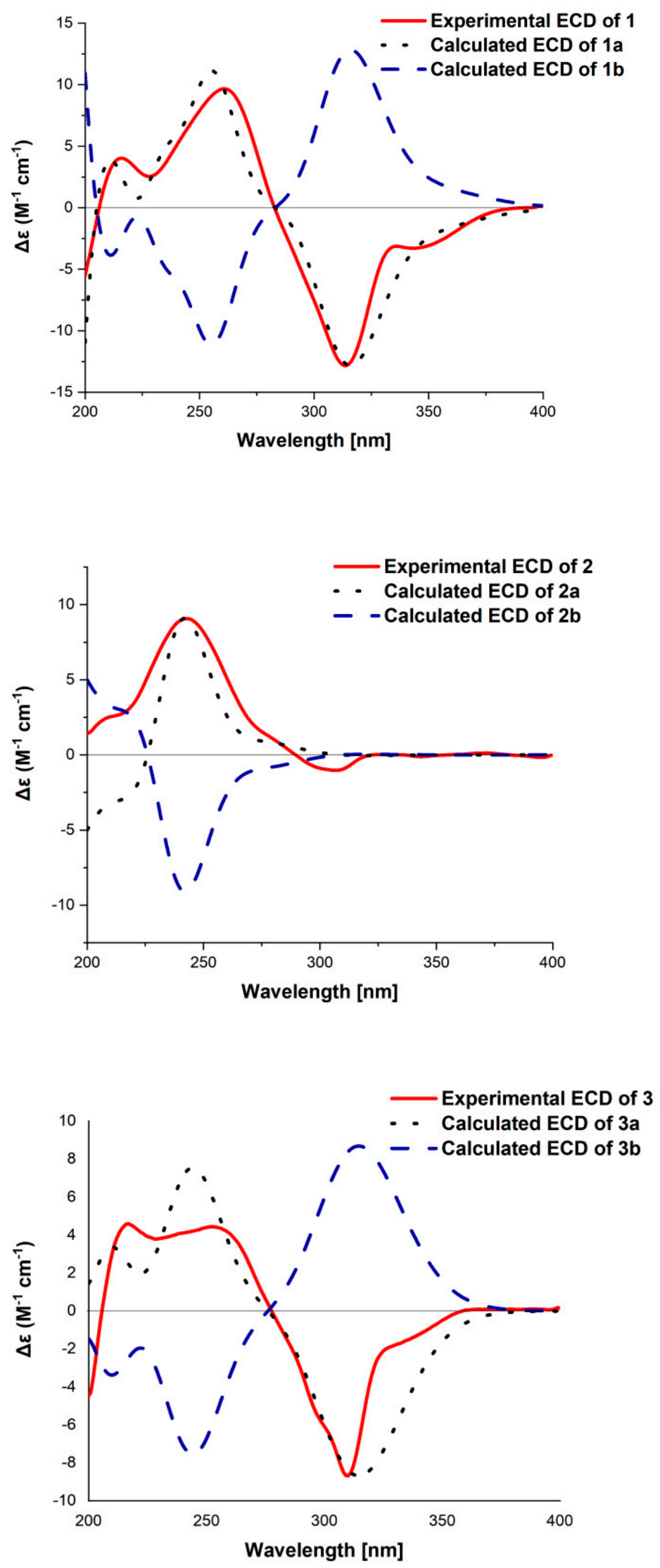

Figure 4. Calculated and experimental electronic circular dichroism (ECD) spectra of 1-3. 
The molecular formula of penimeroterpenoid $\mathrm{C}$ (3) was determined to be $\mathrm{C}_{27} \mathrm{H}_{38} \mathrm{O}_{9}$ (nine degrees of unsaturation) by HRESIMS $\left(\mathrm{m} / z 529.2409[\mathrm{M}+\mathrm{Na}]^{+}\right)$, which is 12 mass units fewer than that of $\mathbf{2}$. Interpretation of the IR and NMR spectroscopic data of $\mathbf{3}$ revealed some structural features similar to those present in 2 . The main differences were that the resonances for one $\mathrm{sp}^{3}$ quarternary carbon $\left(\delta_{\mathrm{C}} 55.1, \mathrm{C}-10\right)$ and one trisubstituted olefin C-9/C-11 $\left(\delta_{\mathrm{H}} / \delta_{\mathrm{C}} 5.55 / 125.8 ; 147.9\right)$ in 2 were replaced by those for one tetrasubstituted olefin C-9/C-10 $\left(\delta_{\mathrm{H}} / \delta_{\mathrm{C}} 132,7 ; 141.9\right)$ and one oxygenated methine $\left(\delta_{\mathrm{H}} / \delta_{\mathrm{C}} 4.75 / 70.8, \mathrm{C}-11\right)$ in the NMR spectra of 3 . In addition, the resonances for the aldehyde group $\left(\delta_{\mathrm{C}} 202.1 ; \delta_{\mathrm{H}}\right.$ 10.1) in 2 disappeared in 3. Such an observation was also confirmed by HMBC correlations (Figure 2) from $\mathrm{H}-5$ to $\mathrm{C}-10, \mathrm{H}-11$ to $\mathrm{C}-8, \mathrm{C}-9, \mathrm{C}-10, \mathrm{C}-12$, and $\mathrm{C}-13$, and from $\mathrm{H}_{3}-25$ to C-7, C-8, C-9, and C-14. Therefore, the planar structure of 1 was established as shown (Figure 1). The relative configuration of $\mathbf{3}$ was also deduced by the NOESY experiment (Figure 3). NOESY correlations of $\mathrm{H}-5$ with $\mathrm{H}-7 \mathrm{a}$ and $\mathrm{H}_{3}-24$ suggested the $\beta$-orientation of these protons, whereas those of $\mathrm{H}-3$ with $\mathrm{H}_{3}-23, \mathrm{H}-11$ with $\mathrm{H}_{3}-20$, and of $\mathrm{H}_{3}-19$ with $\mathrm{H}_{3}-18, \mathrm{H}_{3}-20, \mathrm{H}_{3}-25$, and $\mathrm{H}_{3}-27$ indicated that these protons were $\alpha$-oriented. The absolute configuration for 3 was further determined by a comparison of the experimental and calculated ECD spectra for the enantiomers (3S,5R,8S,11R,12S,13S,14R,16R)-3 (3a) and $(3 R, 5 S, 8 R, 11 S, 12 R, 13 R, 14 S, 16 S)-\mathbf{3}(\mathbf{3 b})$. The calculated ECD spectrum of $3 \mathbf{a}$ was almost consistent with the experimental one (Figure 4). Thus, the absolute configuration of $\mathbf{3}$ was assigned as $3 S, 5 R, 8 S, 11 R, 12 S, 13 S, 14 R, 16 R$.

Two known compounds 4 and 5 were identified as andrastone E (4) [22] and citreohybridonol (5) [11], respectively, by comparing their spectroscopic data with those reported previously in the literature.

Compounds 1-5 were tested for their cytotoxic activities against T24 (human bladder carcinoma cell line), HeLa (human cervical carcinoma cell line), MCF-7 (human breast cancer cell line), HCT116 (human colon cancer cell line), SW480 (human colon cancer cell line), and A549 (human lung carcinoma cell line). Only compound 1 showed cytotoxic to A549, HCT116, and SW480 cell lines, with $\mathrm{IC}_{50}$ values of $82.61 \pm 3.71,78.63 \pm 2.85$, and $95.54 \pm 1.46 \mu \mathrm{M}$, respectively, whereas the corresponding positive control cisplatin showed $\mathrm{IC}_{50}$ values of $14.91 \pm 0.28,20.22 \pm 1.29$, and $27.71 \pm 0.90 \mu \mathrm{M}$, respectively. Compounds 2-4 did not show detectable inhibitory effects on the cell lines tested at $100 \mu \mathrm{M}$.

\section{Experimental Section}

\subsection{General Experimental Procedure}

Optical rotations were measured with an Anton Paar MCP 200 Automatic Polarimeter. Infrared spectra were obtained on a Nicolet IS5 FT-IR spectrophotometer. The 1D/2D NMR spectra were collected from a Bruker Avance-500 spectrometer using solvent signal $\left(\mathrm{CDCl}_{3}\right.$ : $\left.\delta_{\mathrm{H}} / \delta_{\mathrm{C}} 7.26 / 77.2\right)$ as a reference. Mass data were performed on an Agilent Accurate-MassQ-TOF LC/MS 6520 instrument. Semi-preparative HPLC separation was Agilent HPLC instrument-equipped with a diode array detector using a YMC-pack ODS-A $(10 \times 250 \mathrm{~mm}$, $5 \mu \mathrm{m}, 2 \mathrm{~mL} / \mathrm{min}$ ). Open column chromatography (CC) was performed on sephadex LH-20 (Amersham Biosciences, Uppsala, Sweden) and silica gel (200-300 mesh, Qingdao Marine Chemical Factory, Qingdao, China), respectively.

\subsection{Strain and Fermentation}

The strain Penicillium sp. was isolated from a deep-water sediment sample that was collected at a depth of $5115 \mathrm{~m}$ in the East Pacific $\left(145^{\circ} 2^{\prime} \mathrm{W}, 07^{\circ} 37^{\prime} \mathrm{N}\right)$. The isolate was identified as Penicillium sp. by sequencing the internal transcribed spacer (ITS) region of the rDNA (GenBank Accession No. MW767028). Penicillium sp. was grown on potato dextrose agar (PDA) at $27^{\circ} \mathrm{C}$ for five days, and then several pieces of agar plugs (about 0.5 $\left.\times 0.5 \times 0.5 \mathrm{~cm}^{3}\right)$ were added into $250 \mathrm{~mL}$ Erlenmeyer flasks containing $50 \mathrm{~mL}$ of media (glucose $4 \mathrm{~g} / \mathrm{L}$; malt extract $10 \mathrm{~g} / \mathrm{L}$ and yeast extract $4 \mathrm{~g} / \mathrm{L}$ ) at $27^{\circ} \mathrm{C}$ with shaking $(170 \mathrm{rpm}$ ) for five days to produce the seed culture. Finally, Erlenmeyer flasks (500 mL) containing 
$80 \mathrm{~g}$ of rice and $120 \mathrm{~mL}$ of distilled $\mathrm{H}_{2} \mathrm{O}$ and $4.0 \mathrm{~mL}$ seed culture incubated at $25{ }^{\circ} \mathrm{C}$ for 30 days.

\subsection{Extraction and Isolation}

The rice fermentation material was extracted repeatedly with EtOAc $(3 \times 4.0 \mathrm{~L})$, and the organic phases were evaporated to afford an extract $(21.0 \mathrm{~g})$, which was applied to silica gel CC, eluted with a petroleum ether (PE)/acetone gradient system to generate ten fractions (Fr. 1-10). Fr. 10 (1.0 g) was fractionated by normal pressure silica gel CC with PE/EtOAc (from 15:1 to 0:1) to generate six subfractions (Fr. 10-1 to Fr. 10-6). Fr. 10-1 (103 mg) was separated by octadecylsilanized (ODS) CC (20-100\%, MeOH- $\left.\mathrm{H}_{2} \mathrm{O}\right)$ to obtain six subfractions (Fr. 10-1-1 to Fr. 10-1-6). Fr. 10-1-3 was further purified by reversed-phase (RP) high performance liquid chromatography (HPLC; 42-70\% $\mathrm{MeCN} / \mathrm{H}_{2} \mathrm{O}$ for $45 \mathrm{~min}$, $70-100 \% \mathrm{MeCN} / \mathrm{H}_{2} \mathrm{O}$ for $\left.15 \mathrm{~min} ; 2.0 \mathrm{~mL} / \mathrm{min}\right)$ to obatin compounds $1\left(t_{\mathrm{R}} 39.0 \mathrm{~min} ; 5.2 \mathrm{mg}\right)$, $2\left(t_{\mathrm{R}} 33.9 \mathrm{~min} ; 2.0 \mathrm{mg}\right), 3\left(t_{\mathrm{R}} 48.2 \mathrm{~min} ; 2.1 \mathrm{mg}\right)$, and 4 ( $\left.t_{\mathrm{R}} 52.1 \mathrm{~min} ; 2.8 \mathrm{mg}\right)$. Fr. 8 (745 mg) was separated by an open ODS CC, which was eluted with $\mathrm{MeOH} / \mathrm{H}_{2} \mathrm{O}(20-100 \%)$ to obtain nine subfractions (Fr. 8-1 to Fr. 8-9). Fr. 8-8 was further subjected to RP-HPLC (45-60\% MeCN/ $\mathrm{H}_{2} \mathrm{O}$ for $\left.40 \mathrm{~min} ; 2.0 \mathrm{~mL} / \mathrm{min}\right)$ to yield compound $5\left(t_{\mathrm{R}} 27.8 \mathrm{~min} ; 3.8 \mathrm{mg}\right)$.

Penimeroterpenoid A (1): Colorless oil; $[\alpha]_{D}^{25}-79$ (c 0.1, MeOH); UV (MeOH) $\lambda_{\max }$ $(\log \varepsilon): 206.0$ (1.72), $310(0.75) \mathrm{nm} ; \mathrm{CD}\left(c 3.0 \times 10^{-3} \mathrm{M}, \mathrm{MeOH}\right) \lambda \max (\Delta \varepsilon) 314(-12.8), 267$ (+9.6) nm, $216(+4.0) \mathrm{nm}$; IR (neat) $v_{\max }\left(\mathrm{cm}^{-1}\right): 3445,2954,1752,1444,1375,1245,1114$. ${ }^{1} \mathrm{H}$ and ${ }^{13} \mathrm{C}$ NMR data, Table 1 ; HRESIMS $m / z$ 525.2454 $[\mathrm{M}+\mathrm{Na}]^{+}$(calcd for $\mathrm{C}_{28} \mathrm{H}_{38} \mathrm{O}_{8} \mathrm{Na}$, 525.2459).

Penimeroterpenoid B (2): Colorless oil; $[\alpha]_{D}^{25}+24\left(c\right.$ 0.1, MeOH); UV (MeOH) $\lambda_{\max }(\log$

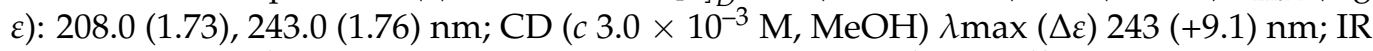
(neat) $v_{\max }\left(\mathrm{cm}^{-1}\right): 3421,2954,1757,1446,1390,1245,1036 .{ }^{1} \mathrm{H}$ and ${ }^{13} \mathrm{C}$ NMR data, Table 1 ;

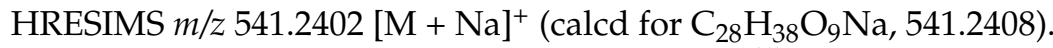

Penimeroterpenoid C (3): Colorless oil; $[\alpha]_{D}^{25}-97$ (c 0.1, MeOH); UV (MeOH) $\lambda_{\max }$ $(\log \varepsilon): 208.0$ (1.76), $308(0.72) \mathrm{nm} ; \mathrm{CD}\left(c 2.0 \times 10^{-3} \mathrm{M}, \mathrm{MeOH}\right) \lambda \max (\Delta \varepsilon) 310(-8.7), 254$ $(+4.4) \mathrm{nm}, 217(+4.6) \mathrm{nm}$; IR (neat) $v_{\max }\left(\mathrm{cm}^{-1}\right): 3477,2954,1753,1446,1376,1243,1036$. ${ }^{1} \mathrm{H}$ and ${ }^{13} \mathrm{C}$ NMR data, Table 1 ; HRESIMS $m / z 529.2409[\mathrm{M}+\mathrm{Na}]^{+}$(calcd for $\mathrm{C}_{27} \mathrm{H}_{38} \mathrm{O}_{9} \mathrm{Na}$, 529.2408).

\subsection{Bioassays for Cytotoxic Activity \\ Cytotoxic assay was performed as previously described [23].}

\subsection{ECD Calculation}

Conformational analyses for compounds 1-3 were performed using Maestro 10.2 in the OPLS3 molecular mechanics force-field within an energy window of 5.0 or $3.0 \mathrm{kcal} / \mathrm{mol}$. The conformers were then further optimized with the software package Gaussian 09 at the B3LYP/6-311G(2d,p), B3LYP/6-31G(d), and B3LYP/6-311G(d,p) level for compounds 1-3, respectively [24], and the harmonic vibrational frequencies were also calculated to confirm their stability. The time-dependent density functional theory (TD-DFT) methods at the CAM-B3LYP/6-31G(2d,p), B3LYP/6-31G(d), and B3LYP/6-311G(d,p) were applied to calculate the 60 lowest electronic transitions which obtained conformers in vacuum, respectively. The Gaussian function was applied to simulate the ECD spectrum of the conformers. The calculated ECD spectra were obtained according to the Boltzmann weighting of each conformer's ECD spectrum in MeOH solution.

\section{Conclusions}

In conclusion, three new andrastin-type meroterpenoids penimeroterpenoids A-C (13) together with two known compounds (4 and 5) were isolated from the fermentation broth of the marine-derived fungi Penicillium sp. The structures of the new compounds were elucidated by mass spectrometry (MS), NMR, and ECD spectroscopic data. Compound 1 showed moderate cytotoxicity against A549, HCT116, and SW480 cell lines. Our findings 
also suggest that the fungal genus Penicillium is a rich source of bioactive secondary metabolites, and thus worthy of in-depth investigations.

Supplementary Materials: The following are available online at https:/ /www.mdpi.com/article/10 $.3390 / \mathrm{md19040189/s1}$, The 1D and 2D NMR spectra of the new compounds 1-3 are supplied.

Author Contributions: All authors conceived the research, analyzed the data, contributed to the study, and approved the final version of the manuscript. L.L. designed the experiments. J.R. and R.H. performed the experiments. R.H., G.L. and L.L. wrote and revised the manuscript. All authors have read and agreed to the published version of the manuscript.

Funding: This work was supported by the National Key R\&D Program of China (2018YFC0311002) and the National Natural Science Foundation of China (32022002, 21772228 and 21977113).

Institutional Review Board Statement: Not applicable.

Informed Consent Statement: Not applicable.

Data Availability Statement: Data is contained within the article or supplementary material.

Conflicts of Interest: The authors declare no conflict of interest.

\section{References}

1. Geris, R.; Simpson, T.J. Meroterpenoids produced by fungi. Nat. Prod. Rep. 2009, 26, 1063-1094. [CrossRef] [PubMed]

2. Matsuda, Y.; Abe, I. Biosynthesis of fungal meroterpenoids. Nat. Prod. Rep. 2016, 33, 26-53. [CrossRef] [PubMed]

3. Matsuda, Y.; Awakawa, T.; Abe, I. Reconstituted biosynthesis of fungal meroterpenoid andrastin A. Tetrahedron 2013, 69, 8199-8204. [CrossRef]

4. Matsuda, Y.; Quan, Z.; Mitsuhashi, T.; Li, C.; Abe, I. Cytochrome P450 for citreohybridonol synthesis: Oxidative derivatization of the andrastin scaffold. Org. Lett. 2016, 18, 296-299. [CrossRef]

5. Uchida, R.; Shiomi, K.; Inokoshi, J.; Tanaka, H.; Iwai, Y.; Omura, S. Andrastins A-C, new protein farnesyltransferase inhibitors, produced by Penicillium sp. FO-3929. J. Antibiot. 1996, 49, 1278-1280. [CrossRef]

6. Kosemura, S.; Matsunaga, K.; Yamamura, S.; Kubota, M.; Ohba, S. The structures of citreohybridone A and B novel sesterterpenoidtype metabolites of a hybrid strain KO 0031 derived from Penicillium citreo-viride B. IFO 6200 and 4692 . Tetrahedron Lett. 1991, 32, 3543-3546. [CrossRef]

7. Kosemura, S.; Matsuo, S.; Yamamura, S.; Citreohybriddione, C. A meroterpenoid of a hybrid strain KO 0031 derived from Penicillium citreo-viride B. IFO 6200 and 4692. Phytochemistry 1996, 43, 1231-1234. [CrossRef]

8. Cheng, Z.B.; Wei, X.B.; Wang, Y.Y.; Bai, S.Y.; Liu, L.J.; Luo, Z.H.; Yuan, W.J.; Li, Q. Two new meroterpenoids and two new monoterpenoids from the deep seaderived fungus Penicillium sp. YPGA11. Fitoterapia 2019, 133, 120-124. [CrossRef]

9. Gao, S.S.; Shang, Z.; Li, X.M.; Li, C.S.; Cui, C.M.; Wang, B.G. Secondary metabolites produced by solid fermentation of the marine-derived fungus Penicillium commune QSD-17. Biosci. Biotechnol. Biochem. 2012, 76, 358-360. [CrossRef] [PubMed]

10. Xie, C.L.; Xia, J.M.; Lin, T.; Lin, Y.J.; Lin, Y.K.; Xia, M.L.; Chen, H.F.; Luo, Z.H.; Shao, Z.Z.; Yang, X.W. Andrastone A from the deep-sea-derived fungus Penicillium allii-sativi acts as an inducer of caspase and RXR $\alpha$-dependent apoptosis. Front. Chem. 2019, 7, 692. [CrossRef]

11. Özkaya, F.C.; Ebrahim, W.; Klopotowski, M.; Liu, Z.; Janiak, C.; Proksch, P. Isolation and X-ray structure analysis of citreohybridonol from marine-derived Penicillium atrovenetum. Nat. Pro. Res. 2018, 32, 840-843. [CrossRef]

12. Kosemura, S.; Meroterpenoids from Penicillium citreo-viride B. IFO 4692 and 6200 hybrid. Tetrahedron 2003, 59, 5055-5072. [CrossRef]

13. Wang, X.R.; Sena, J.G.; Hoover, A.R.; King, J.B.; Ellis, T.K.; Powell, D.R.; Cichewicz, R.H. Chemical epigenetics alters the secondary metabolite composition of guttate excreted by an Atlantic forest soil-derived Penicillium citreonigrum. J. Nat. Prod. 2010, 73, 942-948. [CrossRef]

14. Cheng, X.; Liang, X.; Zheng, Z.H.; Zhang, X.X.; Lu, X.H.; Yao, F.H.; Qi, S.H. Penicimeroterpenoids A-C, meroterpenoids with rearrangement skeletons from the marine-derived fungus Penicillium sp. SCSIO 41512. Org. Lett. 2020, 62, 6330-6333. [CrossRef] [PubMed]

15. Powers, Z.; Scharf, A.; Cheng, A.; Yang, F.; Himmelbauer, M.; Mitsuhashi, T.; Barra, L.; Taniguchi, Y.; Kikuchi, T.; Fujita, M.; et al. Biomimetic synthesis of meroterpenoids by dearomatization-driven polycyclization. Angew. Chem. Int. Ed. 2019, 58, 16141-16146. [CrossRef]

16. Zong, Y.; Wang, W.J.; Xu, T. Total synthesis of bioactive marine meroterpenoids: The cases of liphagal and frondosin B. Mar. Drugs. 2018, 16, 115. [CrossRef]

17. Kuan, K.K.W.; Markwell-Heys, A.W.; Cruickshank, M.C.; Tran, D.P.; Adlington, R.M.; Baldwin, J.E.; George, J.H. Biomimetic synthetic studies on meroterpenoids from the marine sponge aka coralliphaga: Divergent total syntheses of siphonodictyal B, liphagal and corallidictyals A-D. Bioorgan. Med. Chem. 2019, 27, 2449-2465. [CrossRef] 
18. Matsuda, Y.; Awakawa, T.; Wakimoto, T.; Abe, I. Spiro-Ring formation is catalyzed by a multifunctional dioxygenase in austinol biosynthesis. J. Am. Chem. Soc. 2013, 135, 10962-10965. [CrossRef] [PubMed]

19. Matsuda, Y.; Iwabuchi, T.; Wakimoto, T.; Awakawa, T.; Abe, I. Spiro-Ring Formation is catalyzed by a multifunctional dioxygenase in austinol biosynthesis. J. Am. Chem. Soc. 2015, 137, 3393-3401. [CrossRef] [PubMed]

20. Carroll, A.R.; Copp, B.R.; Davis, R.A.; Keyzers, R.A.; Prinsep, M.R. Marine natural products. Nat. Prod. Rep. 2019, 36, 122-173. [CrossRef]

21. Carroll, A.R.; Copp, B.R.; Davis, R.A.; Keyzers, R.A.; Prinsep, M.R. Marine natural products. Nat. Prod. Rep. 2020, 37, 175-223. [CrossRef] [PubMed]

22. Yang, X.W.; Xie, C.L.; Xia, J.M.; He, Z.H. Andrastone compound and its preparation method and application in preparation of antiallergic drug. Patent CN 111217878 A; China, 2020.

23. Liu, L.; Chen, X.X.; Li, D.; Zhang, Y.; Li, L.; Guo, L.D.; Cao, Y.; Che, Y.S. Bisabolane sesquiterpenoids from the plant endophytic fungus Paraconiothyrium brasiliense. J. Nat. Prod. 2015, 78, 746-753. [CrossRef] [PubMed]

24. Frisch, M.J.; Trucks, G.W.; Schlegel, H.B.; Scuseria, G.E.; Robb, M.A.; Cheeseman, J.R.; Scalmani, G.; Barone, V.; Mennucci, B.; Petersson, G.A.; et al. Gaussian 09; revision C 01; Gaussian, Inc.: Wallingford, CT, USA, 2009. 